Article

\title{
Long-Distance Travel and the Urban Environment: Results from a Qualitative Study in Reykjavik
}

\author{
Johanna Raudsepp *, Áróra Árnadóttir, Michał Czepkiewicz and Jukka Heinonen
}

Faculty of Civil and Environmental Engineering, University of Iceland, 107 Reykjavik, Iceland; E-Mails: jor14@hi.is (J.R.), ara32@hi.is (Á.Á.), mcz@hi.is (M.C.), heinonen@hi.is (J.H.)

* Corresponding author

Submitted: 31 December 2020 | Accepted: 15 February 2021 | Published: 9 June 2021

\begin{abstract}
A compact urban form has shown many benefits in efficiency. Yet multiple studies have found that residents of urban, dense, and centrally located areas travel more frequently than those living in suburbs, small towns, or the countryside. As air travel is already causing more emissions than ground transport in many affluent urban locations and is predicted to increase, this pattern could undermine efforts in climate change mitigation. Explanations of these patterns and motivations for long-distance travel connected to the built environment have been examined quantitatively before, but with inconclusive answers. We studied this topic qualitatively in Reykjavik, Iceland, offering an in-depth perspective through semi-structured interviews. Results showed various links between the urban environment and long-distance travel. Some indications of compensatory travel behavior emerged, particularly connected to a lack of quality green areas, hectic urban life, and commuting stress. Compensatory trips were typically domestic. Furthermore, residential preferences seemed connected to leisure travel preferences-living in green neighborhoods was connected to more domestic travel to nature. The results show there are more factors for 'escape' trips than urban density and lack of green spaces. Examples of car-free lifestyles hindering domestic leisure travel were also found. Our study shows how a qualitative approach offers nuanced insight into the travel motivations of urbanites. Considering our results and travel motivation literature, the compensation hypothesis appears to be an overly narrow theoretical framing. Our study supports the conclusion that planning policies should aim at reducing car-dependence. Further research is needed for specific policy recommendations.
\end{abstract}

\section{Keywords}

climate change; compensation hypothesis; Iceland; long-distance travel; Reykjavik; tourism; travel motivation; urban environment

\section{Issue}

This article is part of the issue "Cities, Long-Distance Travel, and Climate Impacts" edited by Jukka Heinonen (University of Iceland, Iceland) and Michał Czepkiewicz (University of Iceland, Iceland / Adam Mickiewicz University in Poznań, Poland).

(C) 2021 by the authors; licensee Cogitatio (Lisbon, Portugal). This article is licensed under a Creative Commons Attribution 4.0 International License (CC BY).

\section{Introduction}

Climate change has become an existential threat to our living environment, vastly due to anthropogenic impact on global systems (Intergovernmental Panel on Climate Change, 2018). Rapidly growing anthropogenic greenhouse gas emissions have caused Earth to behave increasingly unpredictably (Barnosky et al., 2012; Steffen et al., 2018). At the current trajectory, annual greenhouse gas emission will continue to rise, but to reduce the impact of climate change, global greenhouse gas emission needed to peak in 2020 and rapidly decrease afterward (Intergovernmental Panel on Climate Change, 2018; United Nations Environment Programme, 2019).

Cities contribute to about $3 / 4$ of global energyrelated $\mathrm{CO}_{2}$ emissions (Hoornweg, Sugar, \& Trejos Gómez, 2011; Intergovernmental Panel on Climate Change, 2014; Kennedy, Demoullin, \& Mohareb, 2012) and thus have high climate change mitigation potential (Bai et al., 2018; Hertwich \& Peters, 2009; Wiedmann, 
Lenzen, Keyßer, \& Steinberger, 2020). A large part of emissions generated in cities results from transportation, largely attributable to private vehicles (Intergovernmental Panel on Climate Change, 2018; Sims et al., 2014).

Increased density of the built environment and mixed-use neighborhoods have been considered as a path to climate change mitigation in urban areas. This has been suggested to lead to reduced daily travel distances, reduced dependency on cars, and consequently lower emissions from urban transport (Ewing \& Cervero, 2010; Glaeser \& Kahn, 2010; Hall, 2014). However, residents of large cities in central densely built areas tend to engage in more long-distance travel than residents of other areas (Árnadóttir, Czepkiewicz, \& Heinonen, 2019; Czepkiewicz, Heinonen, \& Ottelin, 2018b). Studies in affluent locations indicate that the increase in longdistance travel among downtown dwellers may offset the emission reductions in daily travel (Czepkiewicz et al., 2018a; Ottelin, Heinonen, \& Junnila, 2014, 2017; Reichert, Holz-Rau, \& Scheiner, 2016), and air travel might become the main source of transport-related emissions (Czepkiewicz, Árnadóttir, \& Heinonen, 2019).

Several explanations for this phenomenon have been proposed, such as the compensation hypothesis (e.g., Holden \& Norland, 2005; Næss, 2006), monetary rebound effects related to car ownership (e.g., Ottelin et al., 2014, 2017), access to transport infrastructure (Bruderer Enzler, 2017), geographical clustering of certain lifestyles, attitudes, and socio-demographic characteristics (Czepkiewicz et al., 2018b; Heinonen \& Junnila, 2011), and dispersion of social networks (Mattioli \& Scheiner, 2019). While the connections between the urban environment and local travel behavior have been broadly studied and are well understood (e.g., Ewing \& Cervero, 2010; Næss, 2012; Næss, Strand, Wolday, \& Stefánsdóttir, 2019), the connections between the urban environment and long-distance travel still offer several areas of investigation (Czepkiewicz et al., 2018b). The majority of studies to date have relied on quantitative data while leaving a gap for more in-depth research. Our study takes a qualitative approach, using interviews to explore the possible connections and explain correlations between the urban environment and long-distance travel.

The study is based on 21 interviews with people aged 26-42 living in the Reykjavik Capital Region (Reykjavik) in Iceland, selected from voluntary respondents of a preceding survey (e.g., Czepkiewicz et al., 2019; Czepkiewicz, Heinonen, Árnadóttir, \& Njeru, 2020c; Czepkiewicz, Heinonen, Næss, \& Stefánsdóttir, 2020a; Czepkiewicz, Klaas, \& Heinonen, 2020b). Iceland is an interesting subject for such a study because it is an island with air travel being the main mode of transport to any other country. What is more, $2 / 3$ of its population lives in the capital area, and its highly affluent society is also highly mobile (Czepkiewicz et al., 2019; Icelandic Tourist Board, 2018).

The study demonstrates various links between the urban environment and long-distance travel. The results show some indications of compensatory travel behavior, but the reasons behind it are not completely covered within the compensation hypothesis frame. The study identifies potential areas of improvement for the theoretical framing. The results of the study expand on recent quantitative studies conducted in Reykjavik (e.g., Czepkiewicz et al., 2019, 2020a, 2020b, 2020c) by providing a more nuanced understanding of the travel motivations of Reykjavik urbanites, and uncovering more kinds of causal connections between residential location, the built environment, and long-distance travel.

\section{Background}

The connection between urban density and longdistance travel has been previously highlighted as an unintended side effect of densification (Holden \& Linnerud, 2011; Holden \& Norland, 2005). From this vantage point, it is vital to study the character of relationships between urban form and long-distance travel and determine to what extent the higher level of leisure mobility is due to increased urban density and compactness and to what extent it is a parallel phenomenon that is largely unaffected or only indirectly affected by urban form. In recent years, several studies have provided possible theoretical explanations and some empirical evidence in their support, primarily in Western and Northern European contexts.

\subsection{Monetary Rebound Effect}

The effect is hypothesized to occur when people living in dense urban areas reduce costs and emissions because of structural benefits of urban density, such as smaller living space and a reduced need for car ownership and use, but spend the saved money on consumption of other goods and services, canceling out the benefits (e.g. Heinonen, Jalas, Juntunen, Ala-Mantila, \& Junnila, 2013; Muñiz, Calatayud, \& Dobaño, 2013; Næss, 2012, 2016; Strandell \& Hall, 2015). Ottelin et al. (2014, 2017) further connect reduced car ownership with higher levels of air mobility among middle-income groups of Finnish urbanites and suggest focusing on reducing driving rather than car ownership in urban policies. Conversely, Czepkiewicz et al. $(2019,2020 b)$ found that high rates of air mobility occur particularly among those who drive the most, concluding that the proposed monetary rebound effect is not visible in aggregate travel patterns in this highly affluent locality. Existing qualitative studies conducted in the Icelandic context did not observe shifts in spending between car ownership and flights but pointed to the existence of similar trade-offs in daily consumption and housing costs (Czepkiewicz et al., 2020a).

\subsection{Compensation Hypothesis}

The compensation hypothesis proposes that people who live in densely built and populated urban areas might 
want to 'escape' it or compensate for its deficiencies by traveling more for leisure, either domestically or internationally (e.g., Czepkiewicz et al., 2018a; Holden \& Norland, 2005; Næss, 2006; Strandell \& Hall, 2015). The compensation hypothesis primarily focuses on 'push' factors for traveling (cf. Dann, 1977) related to some deficiencies in the residential environment. As such, it could potentially provide a causal link between urban planning policies and long-distance travel. The deficiencies of the urban environment typically mentioned in this framing include a lack of nature in densely built cities and neighborhoods, and that the travel destinations facilitate contact with nature (Næss, 2006). Studies on the hypothesis have thus far been inconclusive (Czepkiewicz et al., 2020b; Maat \& de Vries, 2006). There are clear examples of seeking nature and calmness as an important motivation of inner-city residents' travel, primarily to domestic destinations in qualitative studies (Czepkiewicz et al., 2020a; Næss, 2006) but quantitative studies show mixed results. Higher urban density and living in a larger city have been related to higher rates of second home access (Große, Fertner, \& Carstensen, 2019) or use (Strandell \& Hall, 2015), but other similar studies did not find such association (Næss, 2006). Access to a private garden and local area density have been associated with less frequent long-distance travel for leisure purposes (Czepkiewicz et al., 2020b; Holden \& Norland, 2005) but the studies have been ambiguous in attributing it to compensatory behavior. Recent studies also show a lack of connection between dissatisfaction with dwellings or residential neighborhoods and long-distance travel (Große et al., 2019). Furthermore, most evidence in favor of the compensation hypothesis applies to domestic trips and not international trips (Große et al., 2019). The compensation hypothesis thus does not appear to be the primary explanation behind the urban density-air travel correlation (Czepkiewicz et al., 2018a).

\subsection{Residential Self-Selection}

Travel-related attitudes and preferences can be a reason for why people choose to live in some areas in the city, which has been described as residential self-selection (Cao, 2014; Czepkiewicz et al., 2018b; Große et al., 2019; Maat \& de Vries, 2006; Næss, 2006). Residential self-selection could also point to an effect opposite to the typical definition of compensation hypothesis, where, for example, residential location is chosen for its green and calm character by people who also enjoy engaging in nature- and calmness-seeking travel outside a city (Czepkiewicz et al., 2020b; Maat \& de Vries, 2006). Therefore, it could prevent the compensation effect from showing in quantitative studies. It has also been hypothesized that nature-related compensatory behavior explains travel patterns only of those who are mismatched with their residential environment (Czepkiewicz et al., 2020b).

\subsection{Cosmopolitan Attitudes}

It has also been proposed that high mobility of urban dwellers results from the concentration of cosmopolitan lifestyles and attitudes in the densest, most lively, and internationally connected city centers of capital and other central cities (Czepkiewicz et al., 2018b, 2019, 2020a, 2020b; Holden \& Norland, 2005; Næss, 2006). Cosmopolitan attitudes describe people's affinity towards experiencing different cultures, exploring the world, and visiting other urban destinations (Czepkiewicz et al., 2018b; Muñiz et al., 2013; Næss, 2006, 2016). These attitudes have been connected to a higher frequency of international flights (Oswald \& Ernst, 2021) and downtown living (Czepkiewicz et al., 2020a, 2020b). Czepkiewicz et al. (2020a, 2020b) suggest that this is the most plausible explanation behind the concentration of high air mobility in urban centers.

\subsection{Social Networks}

Many long-distance trips are taken to maintain and strengthen social connections (Pearce \& Lee, 2005). It has been proposed that high mobility and globalization of social networks is specific for urban lifestyles, especially among the young, affluent, and well-educated urbanites (e.g., Reichert et al., 2016). Some studies point to the importance of previous international mobility and temporary migration (Frändberg, 2014) for predicting air travel intensity (Oswald \& Ernst, 2021). Mattioli and Scheiner (2019) found that first-generation migrants tend to travel more by air than other groups, mostly due to their dispersed social connections.

\subsection{Socio-Demographic and Economic Characteristics}

Socio-demographics could both vary in space and be predictive of travel behavior, e.g., childless and single households tend to live closer to the city center and travel more frequently (Czepkiewicz et al., 2018b; Heinonen \& Junnila, 2011). Tourism and air travel are also highly income-elastic, meaning that the more affluent engage in it to a higher degree than the less affluent (Ivanova \& Wood, 2020; Lenzen et al., 2018). Studies conducted in Iceland (e.g., Czepkiewicz et al., 2019) indicate that high mobility appears in all income groups and that money is not a limiter to travel, so this explanation might not apply to Reykjavik.

This study focuses on the compensation hypothesis as it potentially connects long-distance travel behavior to urban environments more directly compared to other theories. Noticeably, there exist only a small number of qualitative studies (Czepkiewicz et al., 2020a; Næss, 2006), and there is a need for a more nuanced and contextual understanding of the topic (Czepkiewicz et al., 2018b, 2020a, 2020b). Empirical studies have been using a variety of variables to test the compensation hypothesis, but have mostly been inconclusive, while studies 
that include qualitative analysis show examples of travel behavior that underpins the theory (Czepkiewicz et al., 2020a; Næss, 2006). As noted, the compensation hypothesis may only partly explain the connections between the urban environment and travel behavior. Therefore, when studying this topic, one needs to be ready for other explanatory concepts to appear during data analysis (Große et al., 2019; Strandell \& Hall, 2015).

\section{Research Design}

This qualitative study builds on previous quantitative studies focusing on Reykjavik and is situated in a broader sequential mixed-methods research design. These previous studies have identified a geographical trend of higher levels of international air travel among residents of central Reykjavik neighborhoods, partly explained by geographical trends in cosmopolitan attitudes, with room for other explanations (Czepkiewicz et al., 2019, 2020a, $2020 b)$. No statistical support for the compensation hypothesis has been found in the case of domestic travel (Czepkiewicz et al., 2020a, 2020b). Car ownership levels in Reykjavik are very high, with only the immediate downtown area having a higher rate of car-free households (Heinonen, Czepkiewicz, Árnadóttir, \& Ottelin, 2021).

\subsection{Study Area}

The Capital Region of Iceland consists of the city of Reykjavik, which is the country's center of economic, cultural, and administrative activity, and the neighboring municipalities of Kópavogur, Hafnarfjörður, Mosfellsbær, Garđabær, Seltjarnarnes and Kjósarhreppur (Samtök sveitarfélaga á höfuðborgarsvæðinu, n.d.). Reykjavik is the largest urban area in Iceland with a total population of around 230,000 , making up nearly $64 \%$ of the country's total inhabitants (Statistics Iceland, 2020). Several large foreign populations live in Reykjavik, with the Polish population being the largest sub-group (Statistics Iceland, 2019). Reykjavik is currently working with densification as a strategy to limit urban sprawl and reduce the environmental impact (City of Reykjavik, 2014). Today, the city still has a low building density and is sparsely populated when compared to other European cities (World's Capital Cities, 2020). Reykjavik has several large green spaces and a waterfront in and around the city which people enjoy for leisure. The public transport system is based on buses only, and large parts of the urban area are not served with diverse or frequent bus connections. Czepkiewicz, Heinonen, and Árnadóttir (2018c) have defined five transport-related urban zones for the region from pedestrian to bus and car-oriented zones, the car zone having a dominant role (see Figure 1). Population density of the central pedestrian zone is higher than most other areas but similar to some of the less central areas (Czepkiewicz et al., 2018c). However, due to workplace proximity and good walking access to services, the zone allows for a higher share of car-less households than do other zones (Heinonen et al., 2021). In this article, we refer to the central pedestrian zone and its fringe as 'downtown,' 'the city center,' or 'central and dense areas,' and to the remaining zones as 'suburban areas.'

\subsection{Methods}

Data was collected through semi-structured interviews, which were conducted one-on-one at the respondent's chosen location in 2019 and 2020, finishing before Covid-19 restrictions were placed. This method can deepen the understanding of the connections between the urban environment and people's motivations for long-distance travel (Berg, 2009; Berg \& Lune, 2017; Leech, 2002; Ngumbi \& Edward, 2015). Furthermore, several previous studies have called for more qualitative studies on the matter (Czepkiewicz et al., 2019, 2020b; Næss, 2006, 2016). The method aims to complement the recent studies done in Reykjavik which have mainly been using quantitative data (Czepkiewicz et al., 2019, 2020a, 2020b).

Semi-structured interviews allow the researcher to ask further questions if interesting points are raised (Berg, 2009; Ngumbi \& Edward, 2015; Waller, Farquharson, \& Dempsey, 2016). The questions have a guiding function and allow the interviewee to express their thoughts freely within the predetermined topics. These are often in the form of open-ended questions (Berg \& Lune, 2017; Leech, 2002; Ngumbi \& Edward, 2015). Interviewing allows one to see how a person reacts to different topics, which could hint at underlying attitudes (Leech, 2002). On the other hand, there is a risk of misinterpretation of results by the researcher (Leech, 2002). To minimize this risk, extra notes were made during the interviews, and two researchers participated in the interpretation process.

\subsection{Data Collection and Analysis}

Respondents from a previous survey who had volunteered for further research (Czepkiewicz et al., 2019, 2020a, 2020b, 2020c) were contacted to participate in the study. Of those volunteers, people still living in Reykjavik were selected to be interviewed, with an aim for a balanced selection regarding residential location, income level, and car ownership. The interviewees were men and women of various backgrounds between the ages of 26-42. Each interviewee was assigned an ID (for example 11, M40, where 11 stands for the order of the interview, $\mathrm{M}$ for gender 'male' and $\mathrm{F}$ for 'female,' and the last two digits are the age of the person; see Table 1).

A total of 21 interviews were collected, transcribed, and analyzed. The interviews consisted of questions covering the topics of neighborhood and dwelling, daily travel, and travel modes, traveling away from the city domestically and abroad, and lastly, environmental attitudes connected to travel. The interviewees were made 
Residential locations of interview participants in Reykjavík Capital Region and its travel-oriented urban zones

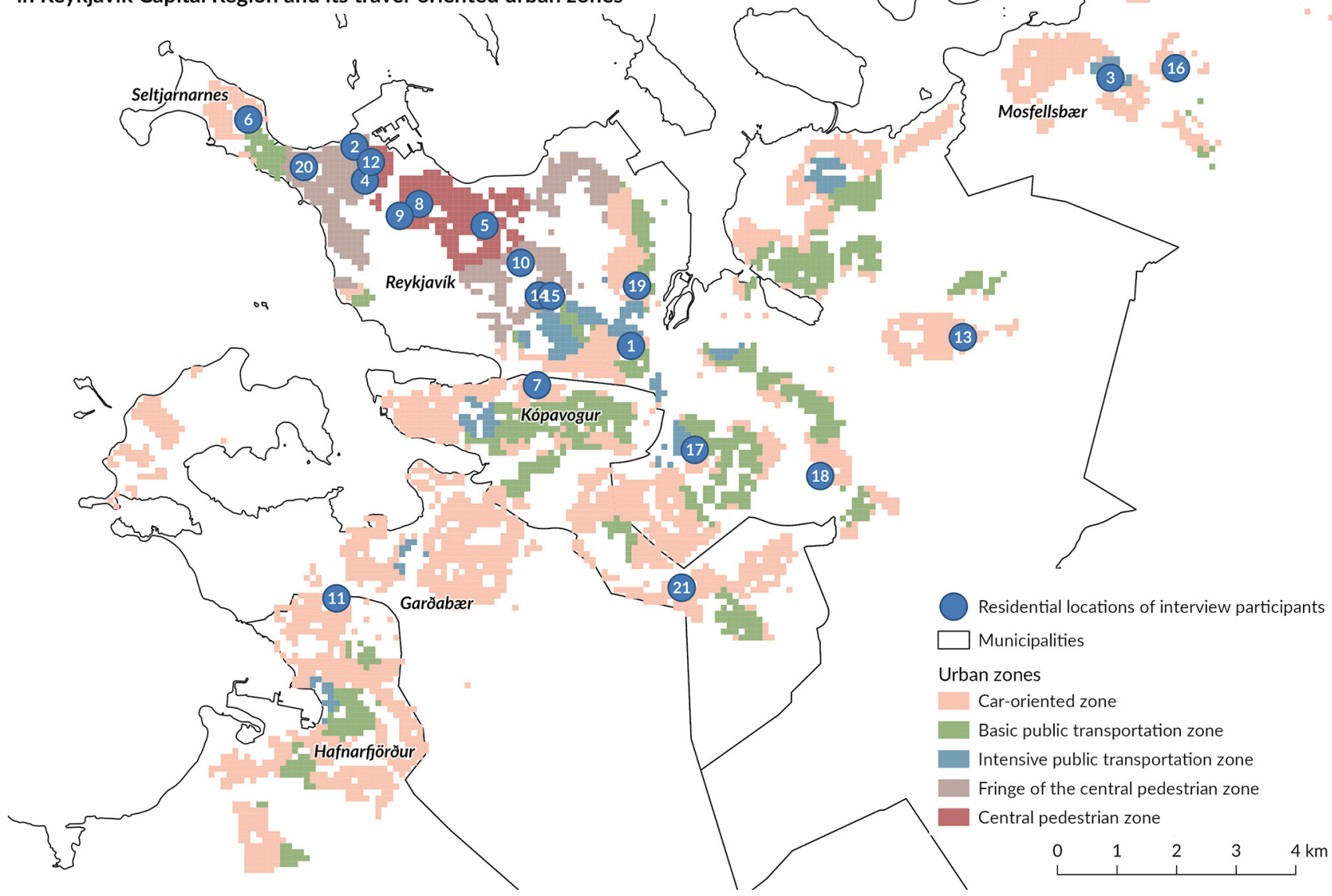

Figure 1. Residential locations of interview participants in Reykjavik Capital Region and its travel-oriented urban zones.

aware beforehand of the broad topics that the questions would cover, but not the specific questions themselves to receive authentic responses. The interviews took between 45 to 90 minutes and were conducted in English, Icelandic or Polish, with the latter two later translated into English by the interviewer whose native language was the language of the interview. The analysis was performed on the English versions only.

For analysis, a two-step interpretation process was followed, as described by Næss (2018) and Czepkiewicz et al. (2020b). The first step was interpreting individual answers to the set of 35 predetermined themes and guiding questions. The second step involved summarizing the individual interpretations into an overall interpretation of each theme. We allowed for new themes to emerge as well. Each interview was interpreted by two researchers: The lead author performed both steps of interpretation, and a second researcher validated them.

\section{Results}

Our results showed various links between the urban environment and long-distance travel. Compensatory behavior was detected, but other causal links emerged as well. Moreover, signs of compensatory behavior through complex causal chains were found, the complexity poten- tially explaining partially why previous quantitative studies have often found no or only weak evidence of compensatory behavior. The presentation of the results is divided into three subsections of urban density, greenness, and broader urban environment.

\subsection{Urban Density, Compactness, and Car Ownership}

Density near people's dwellings was not noted by respondents as bothersome. A few said that they would not like their immediate urban environment to get any denser, but none raised urban density as the reason to travel more. Besides, we found an indirect influence of city compactness on long-distance travel mediated through car ownership (Figure 2A). Residents of the city center can opt for a car-free lifestyle due to proximity to services and workplaces:

I can't stand cars, I preferably want never to be close to them, umm, which is another thing which is a complete luxury [in downtown]. I can walk on the street to work, I just go down one street... it's really calm car traffic, which I really like. (I8, F38)

Yeah, we were looking for [a place in] the central area, where we could be car-free, or pretty much car-free... 
Table 1. Overview of respondents in the study.

\begin{tabular}{|c|c|c|c|c|c|}
\hline ID & Dwelling type & Household type & Car & Employment status & Urban zone \\
\hline I1, M40 & Apartment & Family w. children & Yes & Employed full-time & Basic public transportation \\
\hline I2, F40 & Apartment & Single or other & Yes & Employed full-time & Fringe of the central pedestrian \\
\hline 13, M29 & Detached house & Single or other & Yes & Employed full-time & Intensive public transportation \\
\hline 14, M29 & Apartment & Family w. children & Yes & Employed full-time & Fringe of the central pedestrian \\
\hline I5, F29 & Apartment & Couple & No & Employed full-time & Central pedestrian \\
\hline 16, M41 & Semi-detached house & Family w. children & Yes & Employed full-time & Car-oriented \\
\hline $17, F 40$ & Detached house & Family w. children & Yes & $\begin{array}{l}\text { Self-employed/ } \\
\text { Entrepreneur }\end{array}$ & Car-oriented \\
\hline 18, F38 & Apartment & Family w. children & No & Employed full-time & Central pedestrian \\
\hline 19, F26 & Detached house & Single or other & Yes & Other & Central pedestrian \\
\hline I10, F37 & Apartment & Single or other & Yes & Employed full-time & Fringe of the central pedestrian \\
\hline $\mathrm{I11}, \mathrm{F} 30$ & Detached house & Family w. children & Yes & Employed full-time & Car-oriented \\
\hline I12, M36 & Apartment & Family w. children & Yes & Employed full-time & Central pedestrian \\
\hline I13, F39 & Apartment & Family w. children & No & Unable to work & Car-oriented \\
\hline I14, F36 & Apartment & Family w. children & Yes & Employed full-time & Fringe of the central pedestrian \\
\hline I15, F36 & Other & Family w. children & Yes & Employed full-time & Fringe of the central pedestrian \\
\hline I16, F34 & Apartment & Couple & Yes & Employed full-time & Car-oriented \\
\hline $117, \mathrm{~F} 30$ & Apartment & Couple & Yes & Employed full-time & Basic public transportation \\
\hline I18, F36 & Apartment & Couple & Yes & Student & Car-oriented \\
\hline I19, F42 & Semi-detached house & Family w. children & Yes & Student & Car-oriented \\
\hline 120, F27 & Apartment & Single or other & Yes & Student & Fringe of the central pedestrian \\
\hline I21, F42 & Other & Single or other & Yes & Employed full-time & Car-oriented \\
\hline
\end{tabular}

so it was just that, sort of mainly that with the carlessness and local services. (14, M29)

Several suburban dwellers brought up that they could not live in the city center, since they need a car for something important to them, which is made difficult due to the lack of parking spaces or higher dwelling expenses in the city center. This is illustrated by the following: "I have to say the price is a very strong influence and the size... we have to have parking space as we have so many cars, so we could never go and live downtown Reykjavik" (I18, F36).

A car-free lifestyle can, in turn, limit one's options for domestic travel and thus could encourage more international travel as an alternative. 15, F29, stood out in the study-she has chosen to live in a central area of Reykjavik to enable a car-free lifestyle, although not owning a car means she cannot travel domestically as frequently as she used to when owning a car. On the other hand, living in this environment and not having the possibility for domestic travel makes her feel claustrophobic. Instead, she now takes more trips abroad. She describes her situation as follows:

It's just about cities, there's something like claustrophobia and an overwhelming feeling that I can't stand....[We travel domestically] a lot less since we sold the car. We used to do it a lot....It's expensive to take the bus there.....And that's what I miss-just getting outside a little bit, getting some nature, without having to borrow anything or anything like that. $(15$, F29)

In international travel, city trips for sightseeing and cultural experiences are common among several respondents, but nature trips, particularly to cabins, are preferred domestically. Furthermore, those who own both a car and a cabin in the countryside tend to take frequent domestic trips additionally to international ones. The same people might also choose not to live in the city center, which indicates an indirect causality of the built environment on long-distance travel through car ownership. It can also be deducted that the cost of owning both a cabin and a car might limit one's international travel. An example is I1, M40, who owns a summer house and a car, likes taking four to five trips to the summer house per year, and says going abroad would require saving up: “The salary isn't too high so you know I haven't, or you know I would have to save up, scrape together for a trip, and so that maybe reduces the interest somewhat" (I1, M40).

Other than the two cases observed of central dwellers (18, F38; 14, M29), who had a strong preference for international trips to cities rather than to nature, 
there was no clear connection between residential location and international travel preferences. Both respondents preferred commuting on foot, did not own a cabin, and had no longing for domestic nature trips. Their low car dependence and low expenditure on domestic trips, and their preference for city trips, which are often direct and available for low airfare, might be what resulted in more frequent international leisure travel. All in all, it seems that these factors are strongly interconnected and thus it is difficult to separate one from the other.

\subsection{Greenness}

To capture the potential impact greenness might have on long-distance trips taken by the respondents, the respondents were asked about their perceptions of the greenness of the urban environment in Reykjavik in general and that of the neighborhood they live in. Questions about neighborhood greenness were included both as a potential factor in choosing the current residential location as well as to find out how it was perceived at the time of the interview. Furthermore, they were asked if they possess a yard or have access to one, if they utilize it, and if they feel that this affects their travel choices.

Respondents described Reykjavik to be generally 'green enough' (i.e., I11, F30; I16, F34; I17, F30). The interviews highlighted that the quality of green areas is more important than the access to green areas near their dwellings. If a green area is not inviting, people do not use it and therefore it cannot have a direct impact on their travel behavior.

Access to a private yard or garden was found to have some implications for domestic travel behavior, but less for international. It could be observed that some people who have gardens and use them actively might take fewer domestic trips because of that (i.e., I10, F37; 120, F27; I11, F30):

Yeah, so like, in the summer when I can actually be in my garden, like now it's just a thick layer of snow, I spend more time there, rather than taking these trips, I feel at least. (I20, F27)

There is a lot less stimuli exactly here because l'm just looking at a tree if I look outside... if I was in downtown then there would always be stimuli but here, somehow. Yes, it's just... it maybe has minimized the desire [to travel]. (I10, F37)

Yes, I think it matters less to go someplace else when you've got a nice setup to just be here on the sun deck, or out in the sun. (I11, F30)

Some actively use their garden and travel more domestically, but less internationally (I19, F42; 17, F40; I16, F34; 121, F42). A parallel pattern emerged for these respondents: They are people who have a preference for outdoor activities and being in nature regularly. They have chosen to live in locations with access to a garden or green area (a sign of residential self-selection) and actively enjoy nature (Figure $2 \mathrm{C}$ ). They also take more domestic trips into nature for activities like hiking and skiing. This situation is exemplified by respondent I21, F42, who said: "What I want is [to be] close to nature and a good walking area" when talking about her preferable residential neighborhood qualities, and who likes outdoor activities in both everyday life and away from town.

What is more, interviewees who live in greener areas have mentioned that greenness is good for their wellbeing and reduces their need to travel in general (I17, F30; I10, F37; 120, F27; 19, F26; 17, F40). One interviewee illustrates her neighborhood as follows:

I often feel like during the summer; I feel like I live somewhere in the Nordic countries. There is so much forest in there; this is kind of weird... you just feel the smell of the trees, I don't know what it is completely... you feel like this is a Swedish forest. It's a good feeling. $(\mathrm{I7}, \mathrm{F} 40)$

While the connections between urban green spaces and domestic travel were easier to observe, the connection to international travel could also be noticed. Two cases were observed among residents of the city center (14, $\mathrm{M} 29 ; 18, \mathrm{F38}$ ) where the person does not have any access to a garden and prefers to travel internationally, but they did not make this connection consciously themselves. Interestingly, both these respondents felt that they did not need a garden and both preferred international trips to other cities rather than to natural areas.

\subsection{Stress and Stimuli in the Urban Environment}

Alongside the immediate residential environmental characteristics like density, proximity, and greenness, it was evident from the interviews that broader urban environments and lifestyles can have an impact on leisure travel behavior. Respondents mention stimuli in an environment beyond their dwellings and neighborhood, connected to the pace of life, as something that makes them feel the need to get out of the city (I5, F29; I9, F26; I15, F36; I19, F42; I10, F37) and into nature (I1, M40; I5, F29; I17, F30). Respondents mention a fast-paced lifestyle in the city, bothersome daily commute to work, and a lack of cultural diversity in activities (e.g., restaurants) as push factors for leaving the city:

I suppose it's just to escape for a bit from the tumult of the city....I feel like most Icelanders like getting out into nature a bit. (I1, M40)

Reykjavik -it's not a very big city, but people are really stressed. They drive badly and you know, it's like you... you feel it in the air somehow. So as soon as you get out, it's a completely different pace even though you're not exactly having a cottage in the mountain, 
but just staying in a little village... it's a lot quieter and more calm. (I19, F42)

It's just about cities, there's something like claustrophobia and an overwhelming feeling that I can't stand. $(15$, F29)

Umm, most often it's that I want to get away from the... like a tornado, it can be a bit. It's the culture that you always have to be doing something and go somewhere and la-la-la. (I10, F37)

The explanations people give could further indicate that the stressors or deficiencies in the urban environment (dwellings, neighborhood, general atmosphere) are not something that people actively recognize, often accepting them as a part of regular urban living. Respondent I19, F42 describes a hectic urban atmosphere, adding that "you feel it in the air somehow." Besides, daily commutes to work have been mentioned as bothersome due to long distance from dwellings (I2, F40; I11, F30; I21, F42) and a stressful driving culture (I19, F42). Yet when talking about why they travel, respondents reveal a need for something that the urban environment does not provide for them, whether it be calmness, relaxation, or a general wish for being in nature. As a response to these urban stimuli and stressors, domestic trips, particularly short weekend trips to summer houses, are taken often.

There are also some (e.g., 14, M29; 117, F30) who seek different cultures and therefore travel internationally to other cities for relaxation. One respondent $(I 17, \mathrm{~F} 30)$ provided a comparison of her experience with downtown living and suburban living, saying that there was "nothing to do" and a lack of variety in leisure activity options in her new more suburban area. There seems to be a need for activities and activity spaces near dwellings. The complexity of urban deficiencies might thus explain why compensatory trips are taken to other urban destinations as well as to natural environment locations.

\section{Discussion and Conclusion}

\subsection{Discussion of the Results and Theoretical Contribution}

The findings showed that general push factors of the urban environment play a role in Reykjavik, primarily, a lack of good quality green spaces and urban stress for domestic travel, and a lack of activities and diversity for international travel. The study found some issues with the premise of the compensation hypothesis, which allegedly challenges urban densification policies (Holden \& Linnerud, 2011; Holden \& Norland, 2005). Even though the theory is directly connected to the physical urban environment, it does not provide the most compelling explanation for the relationship between residential location, built environment, long-distance travel patterns in Reykjavik. The results indicate more complex relation- ships between the urban environment and leisure travel behavior. As Næss $(2006,2016)$ has suggested, even if there are indications of a denser urban form being connected to increased leisure travel in some cases, such findings do not necessarily challenge densification as a climate change mitigation strategy. Instead, qualitative studies such as this one might provide the much-needed information to fill the gaps, creating a broader overview of travel motivations among urbanites.

In this study, density was not mentioned by respondents as a push factor for taking more long-distance trips, which challenges the premise of the compensation hypothesis, wherein increased urban density is connected to increased leisure travel (e.g., Holden \& Norland, 2005; Holz-Rau, Scheiner, \& Sicks, 2014; Næss, 2006; Strandell \& Hall, 2015). This could be explained by the relatively low built environment and population density in Reykjavik, compared to other capital cities (World's Capital Cities, 2020). It is still possible that in higher-density cities the negative impacts would be more prominent. A different kind of causal connection between living in a central and dense location and longdistance travel was detected, in which central living encourages car-free lifestyles (see Heinonen et al., 2021, for an in-depth analysis) which in turn hinders domestic travel and encourages international travel instead (Figure 2A). The pattern is also visible in quantitative analyses, in which car ownership was connected to a higher frequency of domestic leisure trips (Czepkiewicz et al., 2020b). This kind of rebound effect is different from the monetary rebound proposed by Ottelin et al. $(2014,2017)$, but works in a similar direction. Our findings show some degree of substitutability between domestic and international travel, which points to the idea of constant monetary or temporal travel budgets that underpin theories of rebound (Czepkiewicz et al., 2018a).

The study also explains why people who live in greener suburbs might be taking more domestic trips than those who live elsewhere. Some of those who enjoy nature and outdoor activities choose to live in a greener area with good access to open spaces, typically suburban, to realize their preferences in both everyday leisure activities and in domestic trips. Suburban locations also enable owning a car, which further facilitates domestic travel (Figure 2B). It exemplifies the tendencies behind the residential self-selection theory (Czepkiewicz et al., 2018b; Große et al., 2019; Maat \& de Vries, 2006; Næss, 2006), which operate in an opposite direction to the typical compensation hypothesis (Czepkiewicz et al., 2020b). In the quantitative study by Czepkiewicz et al. (2020b), high preference for a green residential environment correlated with living away from the city center and close to large green areas and was a significant predictor of a higher frequency of domestic leisure trips. It confirmed that tendencies in residential choices documented in interviews are common and influence the aggregate patterns of leisure travel. Similarly, as in Czepkiewicz et al. 


\begin{tabular}{|c|c|c|c|}
\hline $\begin{array}{l}\text { Dense and } \\
\text { central residential } \\
\text { location }\end{array}$ & $\rightarrow$ Car-free lifestyle & $\begin{array}{c}\text { Decrease } \\
\text { in domestic } \\
\text { leisure travel }\end{array}$ & $\begin{array}{c}\text { Increase } \\
\text { in international } \\
\text { leisure travel }\end{array}$ \\
\hline
\end{tabular}
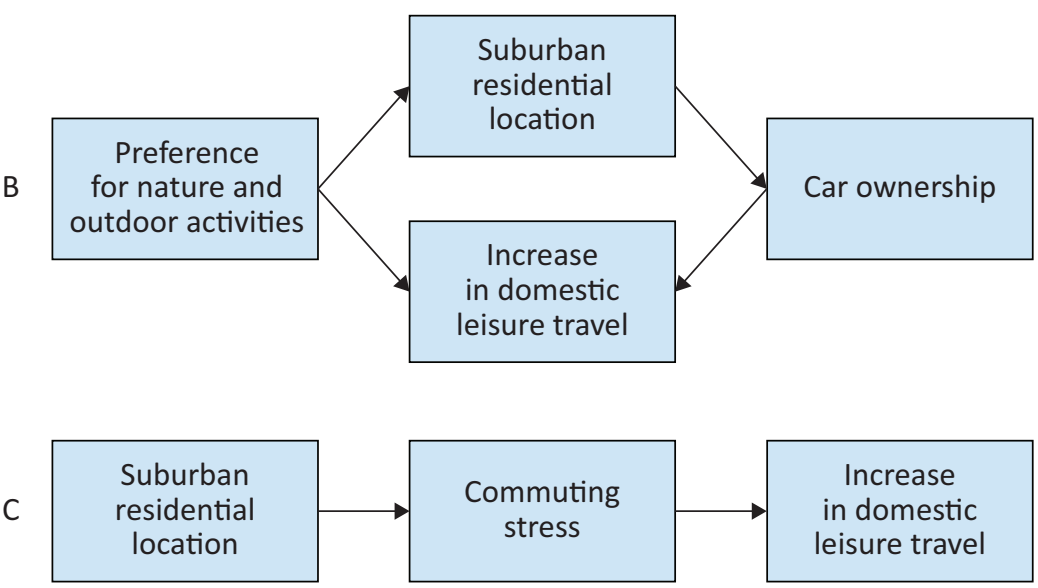

Figure 2. Connections between residential location characteristics and long-distance leisure travel detected in the study.

(2020a), the interviewees in this study were satisfied with their dwellings and/or neighborhood, which suggests a high strength of residential self-selection tendencies in Reykjavik. The age range and good material situation of the respondents might have influenced this as they have a stable living situation, most of them being the owners of their dwellings and therefore probably invested time into choosing a location suitable to their lifestyle, preferences, and needs. This kind of residential self-selection related to nature/outdoors preferences might thus prevent existing examples of compensatory travel behavior from showing in aggregate analyses.

Several respondents noted experiencing stress created by the hectic and fast pace of the city (e.g., I5, F29; I19, F42; I10, F37)-it is "just in the air somehow" (I19, F42). People need to escape the city because of it (I5, F29; I9, F26; I15, F36; I19, F42; I10, F37). Urban stress caused by noise, traffic, pollution, crowding and a hectic environment has been mentioned in studies about compensation hypothesis before (Czepkiewicz et al., 2018b; Næss, 2006; Strandell \& Hall, 2015). Our study strongly suggests that urban stress is an important push-factor for compensation or escaping behavior. A common response was taking short domestic trips, particularly on weekends, into natural destinations with the aim of relaxation and feeling less "stuck" (I6, M41). It was difficult, however, to connect this general stress and pace of urban living with particular residential locations or density levels. There were examples of both inner-city and suburban residents experiencing this kind of effect in our sample. It appears to be a more general urban condition, related to the demands of everyday life that are not directly related to residential location and built environment characteristics on a neighborhood level.

A more direct connection between residential location and the need to escape the city points to the stress associated with long commutes and driving (Figure 2C). This effect is similar to the typical compensation hypothesis but has an inverted meaning for urban planning policies: it is not only densification or compact city policies that would induce escape travel, but also car dependence, which in Reykjavik is particularly high and deeply rooted in its mobility culture (Heinonen et al., 2021). Similarly, as in other cities (Cao, Næss, \& Wolday, 2019; Ewing \& Cervero, 2010), car ownership rates in Reykjavik are lower in centrally located and densely built areas than elsewhere (Heinonen et al., 2021). Our findings thus suggest that the compensation hypothesis should be re-thought and expanded if indeed it is true that long commutes by car induce escape trips rather than, or similarly as, negative side-effects of density. It might be, as suggested in Czepkiewicz et al. (2020b), that different types of urban environments and exposure to them are all connected to motivations to travel away, but the types of trips and modes of travel vary. Our findings also expand on studies that connect commuting with well-being deterioration (Morris \& Guerra, 2014; Stutzer \& Frey, 2008) by adding an environmentally detrimental effect in the form of induced 'escape' trips. Relationships between urban form and leisure travel are further complicated by carownership effects. For instance, I5, F29 chose to move to a central neighborhood to stop using a car, but also says that the city feels "claustrophobic" to her and she needs to get away. However, she cannot revert to her domestic travel habits because she has no car.

It was noticed that lack of greenness and good quality green spaces in Reykjavik could be a push factor motivating domestic leisure trips, which is in line with the compensation hypothesis and previous research (Czepkiewicz et al., 2020b). Holden and Linnerud (2011), and Næss (2006) emphasize the importance of urban green areas' quality for their usage. Participants of this 
study recognized that there are green areas available in their neighborhoods, but they do not use them much. Previous studies on the compensation hypothesis have shown some connection between having a private garden and traveling less domestically, or not having one and traveling more internationally (Czepkiewicz et al., 2020b; Holden \& Norland, 2005; Strandell \& Hall, 2015). The connection also occurs in our study. Similar to the usage of green spaces, active usage of the garden was key in potentially reducing domestic travel.

Our results also showed that the lack of cultural diversity in Reykjavik makes some seek it abroad-an aspect more in line with the cosmopolitan attitudes theory (Czepkiewicz et al., 2018b; Muñiz et al., 2013; Næss, 2006, 2016) and novelty-seeking travel motivations (Pearce \& Lee, 2005). What is more, our study shows that a trip abroad to another urban destination can offer relaxation as well. The compensation hypothesis traditionally considers natural destinations for this purpose, indicating its narrow theoretical scope. Czepkiewicz et al. (2020b) provide quantitative support for this theory by revealing that geographical clustering of high international mobility in Reykjavik's city center is mainly due to the clustering in cosmopolitan attitudes.

Theoretical limitations also pertain to focusing on specific push factors, while overlooking others. Our study indicates that features which one might compensate for, or escape from, extend beyond the residential environment. People interact with diverse urban areas in daily life, and therefore a broader definition of living environment would need consideration. Also, other aspects of urban lifestyles, such as fast pace of life, overstimulation, or general stress of daily life might motivate escape trips, which is noted in travel motivation literature. Crompton (1979) mentions a 'mundane environment' as a push factor, while Pearce and Lee (2005) identify getting away from various stresses, pressures, routines, worries, and everyday demands as important motivations to travel.

Furthermore, the assumption of nature-seeking travel motivation predominates the compensation hypothesis, while tourism literature notes that it is far from dominant, and highlights the importance of noveltyseeking, strengthening personal relationships, and selfdevelopment (Pearce \& Lee, 2005). People also differ in their travel preferences, which makes the compensation hypothesis narrowly applicable. The definition of compensation also typically does not account for other deficiencies created by the built environment such as noise, crowding, pollution, or broader environmental factors, such as lack of sun or harsh weather (Czepkiewicz et al., 2018b). Finally, the primary focus of the compensation hypothesis on the potentially adverse effects of densification obfuscates environmental adversities resulting from car dependence and urban sprawl. Overall, the takeaways from this study and travel motivation literature suggest that the compensation hypothesis is an overly narrow framework that is unlikely to explain a large proportion of leisure trip motivations.

\subsection{Study Limitations}

The authors recognize the limitations of the study. Firstly, predetermined topics and questions in interviews enabled us to explore topics in-depth and link them to previous work (Leech, 2002; Ngumbi \& Edward, 2015), but also limited the emergence of new themes. A similar issue could emerge from the analysis method described by Næss (2018). Secondly, there is a common risk of misinterpreting qualitative data, potentially stemming from cultural or language barriers, or personal bias (Berg \& Lune, 2017; Ngumbi \& Edward, 2015). Thirdly, although a qualitative approach can help explain patterns, the error margin in interpretation means that the strength of evidence is still dependent on the researchers' bias and the context (Leech, 2002). Involving other members of the research team at different stages, however, potentially helped minimize these effects. Fourthly, the interview results cannot be generalized for the whole population (Galvin, 2015). However, simply because there is no strong evidence, it does not mean that a connection is not there (Strandell \& Hall, 2015).

Notably, we did not find much evidence on other hypothesized explanations for the urban form-travel connection, such as cosmopolitan attitudes or globalized social networks. While these issues appear in our interviews, they are not explicitly connected to residential locations. We do not see it, however, as evidence against these explanations, but rather an inability to uncover connections that are not within the conscious reflection of study participants. For instance, people with a cosmopolitan outlook might tend to choose inner-city residential locations (e.g., Czepkiewicz et al., 2020b), without explicitly realizing it. We also observed that respondents struggled with consciously making connections between the urban environment and reasons to travel. Connections, if any, were more often implied, owing to the subconscious nature of motivation.

\subsection{Future Study Recommendations}

The study suggests that a critical evaluation of the definition of the compensation hypothesis is needed. We encourage further conceptual work that would go beyond the narrow framing and elaborate on more diverse links between urban environment and leisure travel. It should be supported with more qualitative or mixed methods studies, including using other qualitative research methods (e.g., focus group interviews). We encourage including the connections identified in our study (Figure 2) in future quantitative studies to assess their prevalence in general samples. Expanding studies on the connection between preferred travel destinations and residential location to include household situations or life stages to better distinguish between preferences on one hand and choices on the other could provide valuable information on the connection. The conscious connections between the urban environment and 
travel behavior could be researched in the field of travel psychology.

Furthermore, we encourage using unified and/or comparable methodologies and expanding the set of environmental characteristics with the perception of noise, air pollution, crowding, commuting stress, and other sources of annoyance and dissatisfaction, not limited to the built environment (e.g., hectic schedules). There is a general need to study push factors connected to everyday life and their influence on both mediumand long-distance leisure travel in the context of reducing travel demand. One might hypothesize that improvements in everyday liveability, such as work time reductions, could minimize the need to 'get away,' but there is currently not enough evidence on the influence of such interventions on travel demand. Further research should also strive to better understand the importance of green space quality and accessibility on meeting the recreational needs of urban dwellers within cities without the need to get away. Particularly relevant for urban planning is studying how cities can strive for reducing cardependence, e.g., through densification, while protecting green spaces and improving equitable access to them for all residents (Haaland \& van den Bosch, 2015).

Other factors, such as cosmopolitan attitudes and social networks, should be explored using qualitative and quantitative methods as well (Mattioli \& Scheiner, 2019; Oswald \& Ernst, 2021). However, one should remember that evidence of these other explanations does not eliminate the possibility of compensating for the deficiencies of the urban environment (Strandell \& Hall, 2015), or vice versa. Czepkiewicz et al. (2018b) note that distinguishing between seeking and escaping behavior within the compensation hypothesis might help better understand links between urban environments and leisure travel. What follows, is the need to consider travel motivations more explicitly in future studies.

\subsection{Policy Relevance}

We identify a link between long commutes by car and escape trips, which suggests that an improved public transport system and reducing travel distances through densification could reduce stress and the need to get away. The issue of car dependence also pertains to domestic travel, as a lack of a private vehicle hinders the possibility to travel within Iceland. On the other hand, reduced car ownership might lead to increased travel by airplane through monetary (Ottelin et al., 2014) or other kinds of substitution. Similarly, policies to reduce everyday life demands, e.g., work time reductions, could potentially limit the need for escape travel, but could also expand travel time budgets and thus encourage more leisure mobility (Kallis, Kalush, Flynn, Rossiter, \& Ashford, 2013). Our results on car-dependence, green spaces, and domestic travel support a common conclusion (e.g., Haaland \& van den Bosch, 2015) that planning policies should aim at reducing car-dependence through com- pact and transit-oriented development while protecting and improving access to quality green areas. Further research is needed before more specific policy recommendations can be formulated.

\section{Acknowledgments}

We thank Vegagerdin (The Icelandic Road and Coastal Administration), the University of Iceland Research Fund, and the Eimskip University Fund for supporting this study.

\section{Conflict of Interests}

The authors declare no conflict of interests.

\section{Supplementary Material}

Supplementary material for this article is available online in the format provided by the authors (unedited).

\section{References}

Árnadóttir, Á., Czepkiewicz, M., \& Heinonen, J. (2019). The geographical distribution and correlates of pro-environmental attitudes and behaviors in an urban region. Energies, 12(8). https://doi.org/ 10.3390/en 12081540

Bai, X., Dawson, R. J., Ürge-Vorsatz, D., Delgado, G. C., Barau, A. S., Dhakal, S., . . . Schultz, S. (2018). Six research priorities for cities and climate change. Nature, 555(7694), 23-25. https://doi.org/10.1038/ d41586-018-02409-z

Barnosky, A. D., Hadly, E. A., Bascompte, J., Berlow, E. L., Brown, J. H., Fortelius, M., . . . Smith, A. B. (2012). Approaching a state shift in Earth's biosphere. Nature, 486(7401), 52-58. https://doi.org/10.1038/ nature11018

Berg, B. L. (2009). Qualitative research methods for the social sciences (7th ed.). Boston, MA: Allyn and Bacon.

Berg, B. L., \& Lune, H. (2017). Qualitative research methods for the social sciences (9th ed.). Boston, MA: Pearson.

Bruderer Enzler, H. (2017). Air travel for private purposes: An analysis of airport access, income and environmental concern in Switzerland. Journal of Transport Geography, 61, 1-8. https://doi.org/10.1016/ j.jtrangeo.2017.03.014

Cao, X. (2014). Residential self-selection in the relationships between the built environment and travel behavior: Introduction to the special issue. The Journal of Transport and Land Use, 7(3), 1-3. https:// doi.org/http://dx.doi.org/10.5198/jtlu.v7i3.726

Cao, X., Næss, P., \& Wolday, F. (2019). Examining the effects of the built environment on auto ownership in two Norwegian urban regions. Transportation Research Part D: Transport and Environment, 67, 
464-474. https://doi.org/10.1016/j.trd.2018.12.020

City of Reykjavik. (2014). Reykjavik municipal plan 2010-2030. Reykjavik: City of Reykjavik Department of Planning and Environment. Retrieved from https://reykjavik.is/sites/default/files/reykjavikmunicipal-plan-2010-2030.pdf

Crompton, J. L. (1979). Motivations for pleasure vacation. Annals of Tourism Research, 6(4), 408-424. https://doi.org/10.1016/0160-7383(79)90004-5

Czepkiewicz, M., Árnadóttir, Á., \& Heinonen, J. (2019). Flights dominate travel emissions of young urbanites. Sustainability, 11(22). https://doi.org/10.3390/ su11226340

Czepkiewicz, M., Heinonen, J., \& Árnadóttir, Á. (2018c). The quest for sustainable Reykjavik capital region: Lifestyles, attitudes, transport habits, well-being and climate impact of young adults (SuReCaRe). Reykjavik: University of Iceland. Retrieved from http:// www.skipulag.is/media/pdf-skjol/SuReCaRe.pdf

Czepkiewicz, M., Heinonen, J., Árnadóttir, Á., \& Njeru, E. W. (2020c). Sustainable Reykjavik capital region 3: Residential location, mobility patterns, and well-being of young adults (SuReCaRe 3). Reykjavik: University of Iceland. Retrieved from https://www.vegagerdin.is/media/rannsoknir/1800689-SuReCaRe-3-report-for-the-Vegagerdin---202003-31.pdf

Czepkiewicz, M., Heinonen, J., Næss, P., \& Stefánsdóttir, H. (2020a). Who travels more, and why? A mixedmethod study of urban dwellers' leisure travel. Travel Behaviour and Society, 19, 67-81. https://doi.org/ 10.1016/j.tbs.2019.12.001

Czepkiewicz, M., Heinonen, J., \& Ottelin, J. (2018b). Why do urbanites travel more than do others? A review of associations between urban form and longdistance leisure travel. Environmental Research Letters, 13(7), 073001. https://doi.org/10.1088/17489326/aac9d2

Czepkiewicz, M., Klaas, V., \& Heinonen, J. (2020b). Compensation or cosmopolitan attitudes: Explaining leisure travel of Nordic urbanites. Travel Behaviour and Society, 21, 167-187. https://doi.org/10.1016/ j.tbs.2020.06.002

Czepkiewicz, M., Ottelin, J., Ala-Mantila, S., Heinonen, J., Hasanzadeh, K., \& Kyttä, M. (2018a). Urban structural and socioeconomic effects on local, national and international travel patterns and greenhouse gas emissions of young adults. Journal of Transport Geography, 68, 130-141. https://doi.org/10.1016/ j.jtrangeo.2018.02.008

Dann, G. M. S. (1977). Anomie, ego-enhancement and tourism. Annals of Tourism Research, 4(4), 184-194. https://doi.org/10.1016/0160-7383(77)90037-8

Ewing, R., \& Cervero, R. (2010). Travel and the built environment: A meta-analysis. Journal of the American Planning Association, 76(3), 265-294. https:// doi.org/10.1080/01944361003766766

Frändberg, L. (2014). Temporary transnational youth migration and its mobility links. Mobilities, 9(1), 146-164. https://doi.org/10.1080/17450101.2013. 769719

Galvin, R. (2015). How many interviews are enough? Do qualitative interviews in building energy consumption research produce reliable knowledge? Journal of Building Engineering, 1, 2-12. https://doi.org/ 10.1016/j.jobe.2014.12.001

Glaeser, E. L., \& Kahn, M. E. (2010). The greenness of cities: Carbon dioxide emissions and urban development. Journal of Urban Economics, 67(3), 404-418. https://doi.org/10.1016/j.jue.2009.11.006

Große, J., Fertner, C., \& Carstensen, T. A. (2019). Compensatory leisure travel? The role of urban structure and lifestyle in weekend and holiday trips in Greater Copenhagen. case studies on transport policy, 7(1), 108-117. https://doi.org/10.1016/j.cstp. 2018.12.004

Haaland, C., \& van den Bosch, C. K. (2015). Challenges and strategies for urban green-space planning in cities undergoing densification: A review. Urban Forestry and Urban Greening, 14(4), 760-771. https://doi.org/10.1016/j.ufug.2015.07.009

Hall, P. (2014). Cities of tomorrow: An intellectual history of urban planning and design since 1880 (4th ed.). Hoboken, NJ: Wiley Blackwell.

Heinonen, J., Czepkiewicz, M., Árnadóttir, Á., \& Ottelin, J. (2021). Drivers of car ownership in a car-oriented city: A mixed-method study. Sustainability, 13(2). https:// doi.org/10.3390/su13020619

Heinonen, J., Jalas, M., Juntunen, J. K., Ala-Mantila, S., \& Junnila, S. (2013). Situated lifestyles: II: The impacts of urban density, housing type and motorization on the greenhouse gas emissions of the middle-income consumers in Finland. Environmental Research Letters, 8(3), 035050. https://doi.org/ 10.1088/1748-9326/8/3/035050

Heinonen, J., \& Junnila, S. (2011). Case study on the carbon consumption of two metropolitan cities. The International Journal of Life Cycle Assessment, 16(6), 569-579. https://doi.org/10.1007/s11367011-0289-3

Hertwich, E. G., \& Peters, G. P. (2009). Carbon footprint of nations: A global, trade-linked analysis. Environmental Science \& Technology, 43(16), 6414-6420. https://doi.org/10.1021/es803496a

Holden, E., \& Linnerud, K. (2011). Troublesome leisure travel: The contradictions of three sustainable transport policies. Urban Studies, 48(14), 3087-3106. https://doi.org/10.1177/0042098010396234

Holden, E., \& Norland, I. T. (2005). Three challenges for the compact city as a sustainable urban form: Household consumption of energy and transport in eight residential areas in the Greater Oslo Region. Urban Studies, 42(12), 2145-2166. https://doi.org/ 10.1080/00420980500332064

Holz-Rau, C., Scheiner, J., \& Sicks, K. (2014). Travel distances in daily travel and long-distance travel: What 
role is played by urban form? Environment and Planning A: Economy and Space, 46(2), 488-507. https:// doi.org/10.1068/a4640

Hoornweg, D., Sugar, L., \& Trejos Gómez, C. L. (2011). Cities and greenhouse gas emissions: Moving forward. Environment and Urbanization, 23(1), 207-227. https://doi.org/10.1177/0956247810392270

Icelandic Tourist Board. (2018). Tourism in Iceland in figures 2018. Reykjavik: Icelandic Tourist Board. Retrieved from https://www.ferdamalastofa.is/ static/files/ferdamalastofa/talnaefni/tourism-iniceland-2018_2.pdf

Intergovernmental Panel on Climate Change. (2014). Climate change 2014 mitigation of climate change: Working group III contribution to the fifth assessment report of the Intergovernmental Panel on Climate Change. Cambridge: Cambridge University Press. https://doi.org/10.1017/CBO9781107415416

Intergovernmental Panel on Climate Change. (2018). Global warming of $1.5^{\circ} \mathrm{C}$ : An IPCC special report on the impacts of global warming of $1.5^{\circ} \mathrm{C}$ above preindustrial levels and related global greenhouse gas emission pathways, in the context of strengthening the global response to the threat of climate change, sustainable development, and efforts to eradicate poverty. IPCC. Retrievef from http://www.ipcc.ch/ report/sr15

Ivanova, D., \& Wood, R. (2020). The unequal distribution of household carbon footprints in Europe and its link to sustainability. Global Sustainability, 3. https:// doi.org/10.1017/sus.2020.12

Kallis, G., Kalush, M., Flynn, H. O., Rossiter, J., \& Ashford, N. (2013). "Friday off": Reducing working hours in Europe. Sustainability, 5(4), 1545-1567. https:// doi.org/10.3390/su5041545

Kennedy, C., Demoullin, S., \& Mohareb, E. (2012). Cities reducing their greenhouse gas emissions. Energy Policy, 49, 774-777. https://doi.org/10.1016/j.enpol. 2012.07.030

Leech, B. L. (2002). Asking questions: Techniques for semistructured interviews. PS: Political Science and Politics, 35(4), 665-668.

Lenzen, M., Sun, Y., Faturay, F., Ting, Y., Geschke, A., \& Malik, A. (2018). The carbon footprint of global tourism. Nature Climate Change, 8, 522-528. https:// doi.org/10.1038/s41558-018-0141-x

Maat, K., \& de Vries, P. (2006). The influence of the residential environment on green-space travel: Testing the compensation hypothesis. Environment and Planning A: Economy and Space, 38(11), 2111-2127. https://doi.org/10.1068/a37448

Mattioli, G., \& Scheiner, J. (2019). The impact of migration background and social network dispersion on air and car travel in the UK. In University of Leeds (Ed.), Conference Proceedings: 51th Annual Universities' Transport Study Group (pp. 1-12). Leeds: UTSG.

Morris, E. A., \& Guerra, E. (2014). Mood and mode: Does how we travel affect how we feel? Transporta- tion, 42(1), 25-43. https://doi.org/10.1007/s11116014-9521-x

Muñiz, I., Calatayud, D., \& Dobaño, R. (2013). The compensation hypothesis in Barcelona measured through the ecological footprint of mobility and housing. Landscape and Urban Planning, 113, 113-119. https://doi.org/10.1016/j.landurbplan.2013.02.004

Næss, P. (2006). Are short daily trips compensated by higher leisure mobility? Environment and Planning B: Planning and Design, 33(2), 197-220. https://doi. org/10.1068/b31151

Næss, P. (2012). Urban form and travel behavior: Experience from a Nordic context. Journal of Transport and Land Use, 5(2), 21-45. https://doi.org/10.5198/ jtlu.v5i2.314

Næss, P. (2016). Built environment, causality and urban planning. Planning Theory \& Practice, 17(1), 52-71. https://doi.org/10.1080/14649357.2015.1127994

Næss, P. (2018). Validating explanatory qualitative research: Enhancing the interpretation of interviews in urban planning and transportation research. Applied Mobilities, 5(2), 186-205. https://doi.org/ 10.1080/23800127.2018.1464814

Næss, P., Strand, A., Wolday, F., \& Stefánsdóttir, H. (2019). Residential location, commuting and nonwork travel in two urban areas of different size and with different center structures. Progress in Planning, 128, 1-36. https://doi.org/10.1016/j.progress.2017. 10.002

Ngumbi, D. E., \& Edward, O. M. (2015). Qualitative interviewing. Scholars Journal of Arts, Humanities and Social Sciences, 3(5B), 1053-1059. https://doi.org/ 10.4135/9781446249420.n5

Oswald, L., \& Ernst, A. (2021). Flying in the face of climate change: Quantitative psychological approach examining the social drivers of individual air travel. Journal of Sustainable Tourism, 29(1), 68-86. https://doi.org/ 10.1080/09669582.2020.181261

Ottelin, J., Heinonen, J., \& Junnila, S. (2014). Greenhouse gas emissions from flying can offset the gain from reduced driving in dense urban areas. Journal of Transport Geography, 41, 1-9. https://doi.org/ 10.1016/j.jtrangeo.2014.08.004

Ottelin, J., Heinonen, J., \& Junnila, S. (2017). Rebound effects for reduced car ownership and driving. Abingdon: Routledge. https://doi.org/10.4324/97813155 98529-15

Pearce, P. L., \& Lee, U.-I. (2005). Developing the travel career approach to tourist motivation. Journal of Travel Research, 43(3), 226-237. https://doi.org/ $10.1177 / 0047287504272020$

Reichert, A., Holz-Rau, C., \& Scheiner, J. (2016). GHG emissions in daily travel and long-distance travel in Germany-Social and spatial correlates. Transportation Research Part D: Transport and Environment, 49, 25-43. https://doi.org/10.1016/j.trd.2016.08.029

Samtök sveitarfélaga á höfuđborgarsvæđinu. (n.d.). Association of municipalities in the Capital area. 
SSH. Retrieved from http://www.ssh.is/index.php? option=com_content\&view=article\&id $=4$

Sims, R., Schaeffer, R., Creutzig, F., Cruz-Núñez, X., D'Agosto, M., Dimitriu, D., ... Tiwari, G. (2014). Transport. In Climate change 2014: Mitigation of climate change: Contribution of working group III to the fifth assessment report of the Intergovernmental Panel on Climate Change (pp. 1-30). Geneva: IPCC. https:// doi.org/10.1017/СBO9781107415416.005

Statistics Iceland. (2019). Population by country of birth, sex and age 1 January 1998-2019. Statistics Iceland. Retrieved from https://px.hagstofa.is:443/ pxenpxen/pxweb/en/Ibuar/Ibuar_mannfjoldi_3_ bakgrunnur_Faedingarland/MAN12103.px

Statistics Iceland. (2020). Population by municipalities, sex and age 1 January 1998-2020: Current municipalities. Statistics Iceland. Retrieved from https://px.hagstofa.is/pxen/pxweb/en/lbuar/ Ibuar_mannfjoldi_2_byggdir_sveitarfelog/ MAN02001.px/table/tableViewLayout1/ ?rxid $=88872389-\mathrm{fe} 18-4 \mathrm{edb}-91 \mathrm{a} 7-7 \mathrm{a} 9624731 \mathrm{bc2}$

Steffen, W., Rockström, J., Richardson, K., Lenton, T. M., Folke, C., Liverman, D., . . Schellnhuber, H. J. (2018). Trajectories of the Earth system in the Anthropocene. Proceedings of the National Academy of Sciences, 115(33), 8252-8259. https://doi.org/10.1073/pnas.

\section{5}

Strandell, A., \& Hall, C. M. (2015). Impact of the residential environment on second home use in Finland: Testing the compensation hypothesis. Landscape and Urban Planning, 133, 12-23. https://doi. org/10.1016/j.landurbplan.2014.09.011

Stutzer, A., \& Frey, B. S. (2008). Stress that doesn't pay: The commuting paradox. Scandinavian Journal of Economics, 110(2), 339-366. https://doi.org/ 10.1111/j.1467-9442.2008.00542.x

United Nations Environment Programme. (2019). The emissions gap report 2019. UNEP. Retrieved from https://wedocs.unep.org/bitstream/handle/ 20.500.11822/30797/EGR2019.pdf?sequence= $1 \&$ isAllowed $=y$

Waller, V., Farquharson, K., \& Dempsey, D. (2016). Qualitative social research: Contemporary methods for the digital age. Los Angeles, CA: SAGE.

Wiedmann, T., Lenzen, M., Keyßer, L., \& Steinberger, J. (2020). Scientists' warning on affluence. Nature Communications, 11, 3107. https://doi.org/10.1038/ s41467-020-16941-y

World's Capital Cities. (2020, July 20). Capital facts for Reykjavik, Iceland. World's Capital Cities. Retrieved from https://www.worldscapitalcities.com/capitalfacts-for-reykjavik-iceland

\section{About the Authors}

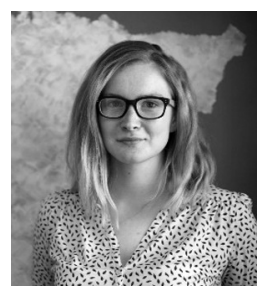

Johanna Raudsepp holds a Master of Science degree in Environment and Natural Resources from the Faculty of Civil and Environmental Engineering at the University of Iceland and a Bachelor of Arts in Economics and Business Administration from the University of Tartu. Her main field of interest is sustainability, with special focus on urban environments, and environmental protection. Johanna currently works as a Marketing Manager at Positium, an Estonian company improving global statistics with mobile positioning data.

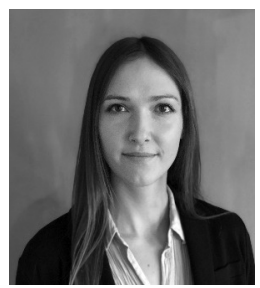

Áróra Árnadóttir is a Doctoral Candidate of Environmental Studies at the University of Iceland, Faculty of Civil and Environmental Engineering. She holds a Bachelor of Arts in Architecture from the Iceland University of the Arts and a Master of Science in Environment and Natural Resources from the University of Iceland. Her research focuses on the impact of urban form and environmental attitudes on environmentally significant behaviors.

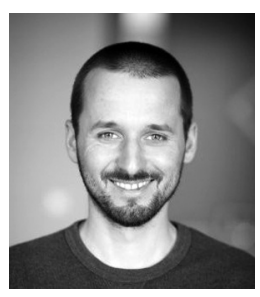

Michał Czepkiewicz (PhD in Earth Sciences sp. Geography) is a Postdoctoral Researcher at the University of Iceland, Faculty of Civil and Environmental Engineering, and a Researcher at Adam Mickiewicz University in Poznań, Department of Sociology. His research focuses on relationships between urban planning, mobility, well-being, and climate impacts. He also works on GIS and online methods that support public participation in urban planning.

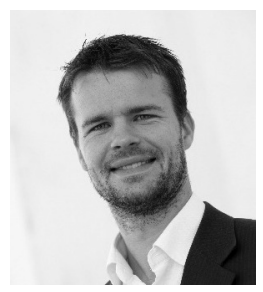

Jukka Heinonen works as a Professor at the University of Iceland, Faculty of Civil and Environmental Engineering. His focus area is sustainability in the built environment. He also holds an Adjunct Professor position at Aalto University in the field of built environment life cycle economics. His main fields of research are consumption-based carbon footprints, urban carbon mitigation and low-carbon human settlements. 